RUNNING HEADER: Multiple Physical Symptoms and Deployment

Abstract: 200 words

Text: 3,069 words

References: 56

Tables/Figures: 4

\title{
Deployment, Combat, and Risk of Multiple Physical Symptoms in the US Military: A
}

\section{Prospective Cohort Study}

Phoebe K. McCutchan, ${ }^{\mathrm{a}, \mathrm{b}} 1$ Xian Liu, ${ }^{\mathrm{a}, \mathrm{b}, \mathrm{c}}$ Cynthia A. LeardMann, ${ }^{\mathrm{b}, \mathrm{d}}$ Tyler C. Smith, ${ }^{\mathrm{e}}$ Edward J.

Boyko, ${ }^{\mathrm{f}}$ Kristie L. Gore, ${ }^{\mathrm{g}}$ Michael C. Freed, ${ }^{\mathrm{a}, \mathrm{c}} 2$ and Charles C. Engel ${ }^{\mathrm{g}}$

${ }^{a}$ Deployment Health Clinical Center, Defense Centers of Excellence for Psychological Health and Traumatic Brain Injury, 1335 East West Hwy, Silver Spring, MD 20910, USA

${ }^{\mathrm{b}}$ Henry M. Jackson Foundation for the Advancement of Military Medicine, Inc., 6720A Rockledge Dr \#100, Bethesda, MD 20817, USA

${ }^{c}$ Department of Psychiatry, Center for the Study of Traumatic Stress, Uniformed Services University of the Health Sciences, 4301 Jones Bridge Rd, Bethesda, MD 20814, USA

d Deployment Health Research Department, Naval Health Research Center, 140 Sylvester Road, San Diego, CA 92106, USA

${ }^{\mathrm{e}}$ Department of Community Health, School of Health and Human Services, National University, 3678 Aero Court, San Diego, CA 92123, USA

${ }^{\mathrm{f}}$ Seattle Epidemiologic Research and Information Center, Veterans Affairs Puget Sound Health Care System, 1600 S. Columbian Way, Seattle, WA 98108, USA

${ }^{\mathrm{g}}$ Behavioral and Policy Sciences, RAND Corporation, 1200 South Hayes Street, Arlington, VA 22202, USA

Correspondence to Phoebe McCutchan, Department of Psychology, American University, 4400 Massachusetts Ave NW, Washington, DC 20016, USA; telephone (410) 978-5535 ; e-mail: phoebe.mccutchan@gmail.com.

${ }^{1}$ Present address: Department of Psychology, American University, 4400 Massachusetts Ave NW, Washington, DC 20016, USA

${ }^{2}$ Present address: National Institute of Mental Health, National Institutes of Health, 6001 Executive Blvd, Bethesda, MD 20892, USA 


\section{ABSTRACT}

Purpose: Multiple physical symptoms (MPS) have historically been observed following deployment to a combat zone and are often disabling in nature. This study examined longitudinal trends in MPS status and its relationship to deployment in US military service members.

Methods: Using longitudinal data from panel 1 participants in the Millennium Cohort Study $(n=$ 76,924), MPS status was assessed at 3 time points (2001-2008) using the 15-item Patient Health Questionnaire. Probability of reporting MPS was analyzed using mixed-effects multinomial logit regression, with time and deployment experience as main explanatory variables.

Results: After adjustment for demographic, military, and health characteristics, service members who deployed with combat were significantly more likely to report MPS at each time point compared with those not deployed (odds ratio [OR] and 95\% confidence interval [CI] for wave 1 $=1.49(1.47,1.52)$, wave $2=1.73(1.69,1.78)$, wave $3=2.08(2.03,2.12))$, and those who deployed without combat (OR and CI for wave $1=2.66(2.59,2.74)$, wave $2=1.81(1.75,1.87)$; wave $3=1.68(1.63,1.74))$.

Conclusions: Longitudinal trends indicate that the probability of reporting MPS has increased consistently over time only for those deployed, regardless of combat experience.

Keywords: signs and symptoms, military medicine, military personnel, veterans health, cohort studies

Abbreviations: DSM-IV, Diagnostic and Statistical Manual of Mental Disorders, 4th Edition; MPS, multiple physical symptoms; OEF, Operation Enduring Freedom; OIF, Operation Iraqi Freedom; PCL-C, PTSD Checklist-Civilian Version; PHQ, Patient Health Questionnaire; PTSD, posttraumatic stress disorder. 
Physical symptom complaints account for more than half of all outpatient encounters in general medical practice $[1,2]$ and are associated with significantly higher health care utilization and costs $[3,4]$, comorbidity [5,6], health status impairment and disability [7-9], and mortality [10]. As in civilian general practice, physical symptoms are commonly reported by patients seeking care in the US Military Health System. According to 2012 surveillance of all active component service members, "symptoms, signs, and other ill-defined conditions" diagnoses represent a leading category for medical encounters and number of individuals affected $[11,12]$. Given the high occurrence in the Military Health System and the demonstrated relationship to negative health outcomes, physical symptoms represent an important health priority for the US military to promote force fitness and retention.

Historically, multiple physical symptoms (MPS) have been observed following deployment to a combat zone, typically in constellations of poorly defined somatic complaints [13-16]. Following the 1991 Gulf War, a significant proportion of service members reported unexplained postwar symptoms, characterized popularly as Gulf War syndrome and later described more rigorously as chronic multisymptom illness [17-20]. However, for reasons yet to be identified, the association between deployment and MPS has been inconsistent [21-27].

After nearly 15 years of conflict in Iraq and Afghanistan, careful and systematic efforts to understand MPS and their relationship to deployment over time among military personnel are sparse. The purpose of this study was to examine the relationship of deployment and combat exposure to subsequent MPS in a longitudinal sample of active duty, Reserve, and National Guard personnel from all branches of the US military.

\section{METHODS}


Study population

The Millennium Cohort Study, the largest longitudinal military study, was launched in 2001 to assess the long-term health effects of military service [28,29]. The population for the current study included the first panel of participants (panel 1) of the Millennium Cohort Study, a probability-based sample of all US military personnel serving as of October 2000, with oversampling for women, members of the Reserve or National Guard, and those who had previously deployed to Southwest Asia, Bosnia, or Kosovo. Data from the first 3 waves of Millennium Cohort data collection were utilized: wave 1 (July 2001-June 2003), wave 2 (June 2004-February 2006), and wave 3 (June 2007-December 2008).

Primary outcome variable: MPS status

MPS status was assessed using the 15-item Patient Health Questionnaire (PHQ; see Figure 1) [30,31]. The first 13 items are rated on a 0 to 2 scale for the past month; the remaining 2 items, sleeping trouble and fatigue, are rated on a 0 to 3 scale for the past 2 weeks and were adapted to the 0 to 2 response scale using the validated approach of Kroenke and colleagues [31,32]. Using Millennium Cohort data the Somatoform Disorders subscale (which composes 13 of the 15 items from the PHQ-15) was found to have satisfactory internal consistency $($ Cronbach's $\mathrm{a}=0.76)$ [33]. This method yields total scores ranging from 0 to 30 for women and 0 to 28 for men. In the current study, we derived MPS status (positive or negative) based on a cut point score of $\geq 10$, which represents a moderate to high level of somatic symptom severity [31].

Main explanatory variable: Deployment group 
Deployment in support of Operation Iraqi Freedom (OIF) and Operation Enduring Freedom $(\mathrm{OEF})$ was derived from Department of Defense personnel files obtained from the Defense Manpower Data Center and based on receiving imminent danger pay, hardship duty pay, or combat zone tax exclusion benefits. Participants were classified as having recent deployment if records indicated at least 1 day of deployment in support of OIF/OEF in the 3-year interval prior to each respective wave survey date. Among those deployed, combat-related experience was based on at least 1 affirmative response to questions about witnessing death, trauma, injuries, prisoners of war, or refugees in the last 3 years. The main explanatory deployment group variable classified individuals as 1) not deployed, 2) deployed without combat experience, or 3) deployed with combat experience. Deployment group was defined as a timevarying characteristic measured at each wave with an observation window of 3 years prior to the respective wave.

Covariates

Demographic and military-specific data were obtained at baseline from electronic personnel files maintained by the Defense Manpower Data Center and included sex, date of birth, race/ethnicity, military rank, service component, and service branch.

Depression was assessed as a time-dependent variable using the 9 depression items of the PHQ [30,34] and a question that asked participants if they had ever (baseline) or in the last 3 years (wave 2 and 3 ) been diagnosed with depression by a health professional. The PHQ items were scored using an algorithm that corresponds to the Diagnostic and Statistical Manual of Mental Disorders, 4th Edition (DSM-IV) [35] depression diagnosis criteria. For each wave, 
participants who screened positive for depression on the PHQ items or reported a depression diagnosis were classified as having depression.

Posttraumatic stress disorder (PTSD) was assessed as a time-dependent variable using the 17-item PTSD Checklist-Civilian Version (PCL-C) [36] and a question that asked participants if they had ever (baseline) or in the last 3 years (waves 2 and 3) been diagnosed with PTSD by a health professional. The PCL-C items were scored using an algorithm that corresponds to the DSM-IV PTSD diagnosis criteria [35]. For each wave, participants who screened positive on the PCL-C or reported a PTSD diagnosis were classified as having PTSD.

Panic or other anxiety syndromes was assessed as a time-dependent variable using 15 panic items and 6 generalized anxiety items from the PHQ. For each wave, responses were classified as a positive screen if they met PHQ-defined criteria for panic and/or other anxiety [30,37].

A count of participants' reported physical conditions was assessed as a time-dependent continuous variable derived from self-report of ever (baseline) or in the last 3 years (waves 2 and 3) being diagnosed with any of 24 serious or chronic physical conditions [38].

Statistical analysis

Descriptive analyses were conducted to compare demographic and behavioral characteristics between the 3 outcome categories (MPS positive, MPS negative, or attrition [death or dropout between 2 successive waves]). Unadjusted analyses, including chi-square tests, were used to calculate measures of association of MPS with deployment, occupational, demographic, and behavioral characteristics.

In light of existing theories on deployment and mental health, we specified a set of control variables in the regression analysis to adjust for possible confounding effects in 
describing longitudinal trajectories of MPS, including 5 sociodemographic control factors (age, sex, race/ethnicity, pay grade, and service branch) and 4 time-varying health variables (depression, PTSD, anxiety/panic, and number of physical conditions); all control variables were rescaled to be centered at sample means for analytic convenience. Prior deployment and cumulative duration of deployment were both considered as potential predictors on the association of interest (i.e., MPS and deployment); however, these variables did not have any additive effect on MPS when the present control variables are considered, and thus were removed from the model. A combination of time and time $\times$ time, the so-called quadratic polynomial time function, as well as time $\times$ deployment interaction were considered for capturing the changing pattern of the longitudinal trajectories in MPS. Because the outcome variable consisted of 3 nominal levels, a mixed-effects multinomial logit regression model was performed using the probability of falling in a given MPS category, with time and deployment experience as the main explanatory variables. Given 3 response levels, we applied the mixedeffects multinomial logit model on 2 logit components, using time, deployment group, and other covariates as the independent variables. Using the adaptive Gaussian quadrature, both the fixed and random effects for the mixed-effects multinomial logit model were estimated. The impact of missing cases on MPS status was adequately handled by applying the empirical Bayesian approach in longitudinal data analysis [39]. With respect to dropouts at waves 2 and 3, mixedeffects modeling techniques are robust to missing data in derivation of parameter estimates [40].

The conditional odds ratio was computed from these models using the predicted probabilities involved in the 2 odds terms, rather than directly from the antilog transformation of the corresponding regression coefficient. The statistical procedures for computing the predicted 
probabilities, the conditional odds ratios, and their respective standard errors, are described in Liu and Engel [40].

Data management and statistical analyses were performed using SPSS statistical software, version 20 (IBM, Armonk, NY), and SAS software, version 9.3 (SAS Institute Inc., Cary, NC).

\section{RESULTS}

Of the 76,924 eligible participants who completed the wave 1 survey, 54,954 (71\%) completed the wave 2 follow-up survey and 54,728 (71\%) completed the wave 3 follow-up survey. Observations (each participant was supposed to have 3 observations) were excluded from the analysis if MPS status was indeterminable (i.e., they did not provide complete PHQ-15 responses; $n=986$ for wave 1,972 for wave 2, and 746 for wave 3). An additional 4 participants lacked any useable data in fitting the longitudinal model and were thus excluded at baseline, resulting in a total of $75,934,53,982$, and 53,982 observations available for analysis at each respective wave. Characteristics of the Millennium Cohort participants at baseline (wave 1) are presented in Table 1. Of the participants included in the descriptive analysis, $8.7 \%, 9.9 \%$, and $12.5 \%$ were characterized as having MPS at waves 1, 2, and 3, respectively.

In the application of the mixed-effects multinomial logit model, individuals who deployed but whose combat experience status was indeterminable (i.e., they did not provide responses to respective exposure questions; waves $1(n=46), 2(n=241)$, and $3(n=135)$, respectively) were included in the deployed without combat group after multiple analyses indicated that there was no difference in the analytic results between this method and exclusion. The inclusion of time $\times$ time and time $\times$ deployment interactions did not contribute significantly 
to the model fit, and thus were removed. The remaining variables from Table 1 and the random effects were all very strongly statistically significant in the mixed-effects multinomial logit model and included as covariates in subsequent models.

Figure 2 displays the probabilities of MPS by deployment group over the 3 waves. For those not deployed, the probability of MPS, or MPS prevalence at each wave, is not distinctly associated with time since it stabilizes at about $7 \%$. For those deployed with combat experience, the probability of MPS at baseline is about $10 \%$, considerably higher than for the other 2 groups, and then it increases steadily to about $11 \%$ in 2004 and about $13 \%$ in 2007 . The pattern for those deployed without combat is similar to those who deployed with combat, though at a much lower level. More specifically, MPS prevalence for this deployment group increases from 4\% in 2001 to about $7 \%$ in 2004 and further to about $8 \%$ in 2007.

Table 2 presents the conditional MPS odds ratios and their respective $95 \%$ confidence intervals for 3 deployment groups at each wave. The adjusted odds ratios for the 3 deployment groups at the 3 waves are all statistically significant. The conditional odds ratios for those deployed with combat experience versus each of the other 2 deployment groups are all well above unity (range 1.5 - 2.7), demonstrating consistent and robust elevated risk of developing MPS in those deployed with combat experience. The largest odds ratio (odds ratio $[\mathrm{OR}]=2.7$ ) is found at baseline (wave 1), suggesting a 2.7 times increase in the individual odds of having MPS for a person deployed with combat experience compared with those who deployed without combat experience, other covariates being constant at average conditions. Between those deployed without combat and those not deployed, the pattern is less consistent. At the first 2 time points, the MPS conditional odds ratios are smaller than unity, thus highlighting lower individual odds of having MPS among those deployed without combat $(\mathrm{OR}=0.56$ at wave 1 and 0.96 at 
wave 2); at the third time point, however, the pattern is reversed, with higher odds among those deployed without combat $(\mathrm{OR}=1.23)$.

\section{DISCUSSION}

Using data from the largest and most extensive longitudinal epidemiologic military health survey conducted to date, these analyses demonstrate a consistent and robust longitudinal association between service members' reports of combat experience during deployment and the occurrence of MPS. Interestingly, deployment without combat experience was not consistently associated with an increase in risk of MPS, suggesting the most important risk factor was combat exposure. In addition to higher odds of MPS among the combat-deployed group, we also found that the probability of MPS increased over time for both combat and non-combat-deployed groups, a trend that was not observed among nondeployed personnel. While we did not examine number of deployments or cumulative duration of deployment in this study, increases over time may indicate that the sustained conflicts may be giving rise to more complaints of physical symptoms among those who deploy. It is certainly conceivable that analyses including later (i.e., post-2007) waves of data from this cohort will demonstrate an increased risk of MPS for noncombat deployment as well, given the longitudinal trend of probabilities observed in the current analysis.

The findings from this study are consistent with a recent examination of chronic multisymptom illness in Millennium Cohort Study participants [23], but they contradict a second study by Quartana et al. [24] of US soldiers deployed to Iraq that found only an indirect relationship between combat and MPS through PTSD, depression, and insomnia. The current findings that increased MPS reporting was associated with combat experience even after 
adjusting for psychological morbidity may reflect sample differences (e.g., population-based vs. only Army, average deployment length), methodological differences (e.g., length of follow-up window, MPS classification), and sample size (<600 vs. approximately 75,000$)$. These results stand in contrast to the early Iraq and Afghanistan war findings among British and Danish military personnel, in which conflict participation was not associated with subsequent physical symptoms $[21,22]$. This may be attributable to the higher levels of combat exposure among the US deployed troops, a finding noted in similar comparisons of PTSD rates between US and UK militaries [41]. Our study findings would suggest that generally lower levels of combat exposure during OIF/OEF deployments could lead to little or no elevation in conflict-related MPS in these troops. This proposition is supported by a 2014 study that directly compared the health outcomes of US and UK military personnel deployed to Iraq in 2007-2008 and found no difference in MPS reporting when stratified by combat exposure level [42].

The longitudinal increases in probabilities of developing MPS associated with noncombat and combat deployment found in this study may appear small, but they have significant implications when applied across an entire military population of over 2.2 million active duty, Reserve, and National Guard members [43]. Several studies have shown that MPS is associated with significant increases in morbidity, mortality, and health care use [3-10], suggesting that the increase in MPS observed among deployed individuals may not only have adverse long-term effects on service member health and well-being, but also on the entire force readiness and later the civilian work force as these individuals separate from military service. Indeed, despite the rigorous health criteria required for entrance into the military, there is evidence that veterans and military service members are experiencing physical health declines faster than age-adjusted population norms in the years following deployment [44]. 
Given the long history of postwar physical symptom syndromes among war veterans and the common and disabling nature of physical symptoms in general, the Military Health System should consider care models that can maximize functioning in service members who return from combat and develop these symptoms. Many experts have recommended shifting the clinical paradigm away from focusing solely on etiologic cause and toward encouraging providers to consider a biopsychosocial approach to symptom-focused management [45-47]. Models such as stepped care and collaborative care have been shown to be effective in this respect [48-51]. An emphasis on early identification of symptoms and engagement in care following deployment may also minimize declines in physical health associated with delay in visiting a treatment clinic [44].

A potential limitation of the current study is that the population consists of a sample of respondents to the Millennium Cohort questionnaire and may not be representative of the entire military population. However, investigation of several key potential biases in the Millennium Cohort has found the Cohort to be mostly representative, specifically with respect to health care use prior to study enrollment among responders compared with nonresponders, with reliable reporting of data by study participants [33,52-55]. Additionally, a previous study examining weighting for nonresponse among panel 1 members of this cohort indicated that prevalence rates of key outcomes are comparable to results of unweighted analysis [56]. A second limitation of this study is that we cannot be certain of the temporal relationship between deployment and symptoms, given that MPS status can change in the three-year interim between waves. Third, we cannot ascertain whether MPS can be attributed to an underlying condition (i.e., whether they are “medically unexplained"), although our statistical model did adjust for a range of serious and chronic physical conditions. 
Despite these limitations, there are many strengths of this study. The large sample size of this study allows for robust analyses of MPS. This study was one of the first to prospectively analyze MPS in relation to the recent operations in Iraq and Afghanistan among US military personnel, allowing elucidation of the temporal sequence. This cohort consists of participants from all military services and includes active duty, Reserve, and National Guard members, as well as service members who have left the military. Methodologically, this analysis is the first study to focus on military personnel that derives the predicted probabilities, conditional effects, and conditional odds ratios from an integrated statistical framework.

\section{CONCLUSIONS}

The findings of this study indicate that combat deployment to Iraq and Afghanistan is associated with an increased risk of developing MPS in US service members compared with noncombat deployment or nondeployment. Additionally, longitudinal trends demonstrate a consistent increase in probabilities of developing MPS over time for those deployed, regardless of combat experience. This study offers a glimpse into the relationship between deployment and MPS; future systematic efforts to understand MPS among military personnel will provide useful data for developing health policies and programs, especially for those who seek care with deployment-related health concerns. Intensified efforts to understand MPS in the military may also foster trust between service members and the government agencies that provide benefits and health care for them. 


\section{ACKNOWLEDGMENTS}

In addition to the authors, the Millennium Cohort Study Team includes Richard Armenta PhD, Lauren Bauer MPH, Madeline Cross, James Davies, CPT Carrie Donoho PhD, CDR Dennis Faix MD, Lt Col Susan Farrish MD, Toni Geronimo, Kathleen Gunn, William Lee, Hector Lemus PhD, Gordon Lynch, Denise Lovec-Jenkins, David Luxton PhD, Danielle Mitchell, Kristin Motylinski, Anna Nagel MPH, Chiping Nieh PhD, Chris O’Malley MPH, Serguey Parkhomovsky, Anet Petrosyan, Christopher Phillips MD MPH, Teresa Powell MPH, Ben Porter PhD, Rudy Rull PhD, Kari Sausedo MA, Beverly Sheppard, Steven Speigle, Evelyn Sun MPH, Valerie Stander PhD, Laura Tobin MPH, Daniel Trone PhD, Jennifer Walstrom, from the Deployment Health Research Department, Naval Health Research Center, San Diego, CA. We thank Hector Lemus, PhD (Naval Health Research Center, San Diego, CA) for his contribution in providing statistical support and consultation for this study. In addition, we thank Michelle LeWark from the Naval Health Research Center (San Diego, CA) for her technical review and editing of this paper. We appreciate the support from the Management Information Division, US Defense Manpower Data Center (Seaside, CA); Military Operational Medicine Research Program and US Army Medical Research and Materiel Command (Fort Detrick, MD).

The Millennium Cohort Study is funded through the Military Operational Medicine Research Program of the US Army Medical Research and Materiel Command, Fort Detrick, Maryland (supported by the Department of Defense, under work unit no. 60002). The Deployment Health Clinical Center provided funding for Ms. McCutchan, Dr. Liu, Dr. Gore, and Dr. Freed's efforts in this project. VA Puget Sound Health Care System provided support for Dr. Boyko’s participation in this research. The funding organizations had no role in the design and conduct of 
the study; collection, analysis, or preparation of data; or preparation, review, or approval of the manuscript.

The views expressed in this article are those of the authors and do not reflect the official policy or position of the Deployment Health Clinical Center, Uniformed Services University of the Health Sciences, Department of the Navy, Department of the Army, Department of the Air Force, Department of Defense, Department of Veterans Affairs, Department of Health and Human Services, National Institutes of Health, National Institute of Mental Health, or the US Government. US Government Work (17 USC 105). Not copyrighted in the US. Approved for public release; distribution is unlimited. This research has been conducted in compliance with all applicable federal regulations governing the protection of human subjects in research (Protocol NHRC.2000.0007). 


\section{REFERENCES}

[1] Schappert SM. National Ambulatory Medical Care Survey: 1989 summary. Vital Health Stat 13. 1992(110):1-80.

[2] Kroenke K, Price RK. Symptoms in the community. Prevalence, classification, and psychiatric comorbidity. Arch Intern Med. 1993;153(21):2474-80.

[3] Kisely S, Simon G. An international study comparing the effect of medically explained and unexplained somatic symptoms on psychosocial outcome. J Psychosom Res. 2006;60(2):125-30. [4] Barsky AJ, Orav EJ, Bates DW. Somatization increases medical utilization and costs independent of psychiatric and medical comorbidity. Arch Gen Psychiatry. 2005;62(8):903-10. [5] Kroenke K, Spitzer RL, Williams JB, Linzer M, Hahn SR, deGruy FV, 3rd, et al. Physical symptoms in primary care. Predictors of psychiatric disorders and functional impairment. Arch Fam Med. 1994;3(9):774-9.

[6] Kroenke K, Jackson JL, Chamberlin J. Depressive and anxiety disorders in patients presenting with physical complaints: clinical predictors and outcome. Am J Med. 1997;103(5):339-47.

[7] Escobar JI, Golding JM, Hough RL, Karno M, Burnam MA, Wells KB. Somatization in the community: relationship to disability and use of services. Am J Public Health. 1987;77(7):83740.

[8] Hoedeman R, Blankenstein AH, Krol B, Koopmans PC, Groothoff JW. The contribution of high levels of somatic symptom severity to sickness absence duration, disability and discharge. J Occup Rehabil. 2010;20(2):264-73.

[9] Creed FH, Davies I, Jackson J, Littlewood A, Chew-Graham C, Tomenson B, et al. The epidemiology of multiple somatic symptoms. J Psychosom Res. 2012;72(4):311-7. 
[10] Engel CC, Jr., Liu X, Hoge C, Smith S. Multiple idiopathic physical symptoms in the ECA study: competing-risks analysis of 1-year incidence, mortality, and resolution. Epidemiological Catchment Area. Am J Psychiatry. 2002;159(6):998-1004.

[11] Armed Forces Health Surveillance Center (AFHSC). Signs, symptoms, and ill-defined conditions, active component, U.S. Armed Forces, 2000-2012. MSMR. 2013;20(4):25-8; discussion 6-8.

[12] Armed Forces Health Surveillance Center (AFHSC). Absolute and relative morbidity burdens attributable to various illnesses and injuries, U.S. Armed Forces, 2012. MSMR. 2013;20(4):5-10; discussion 8-.

[13] Hyams KC, Wignall FS, Roswell R. War syndromes and their evaluation: from the U.S. Civil War to the Persian Gulf War. Ann Intern Med. 1996;125(5):398-405.

[14] Jones E, Wessely S. Hearts, guts and minds: somatisation in the military from 1900. J Psychosom Res. 2004;56(4):425-9.

[15] Jones E, Wessely S. Psychiatric battle casualties: an intra- and interwar comparison. Br J Psychiatry. 2001;178:242-7.

[16] Jones E. Historical approaches to post-combat disorders. Philos Trans R Soc Lond B Biol Sci. 2006;361(1468):533-42.

[17] Fukuda K, Nisenbaum R, Stewart G, Thompson WW, Robin L, Washko RM, et al. Chronic multisymptom illness affecting Air Force veterans of the Gulf War. JAMA. 1998;280(11):981-8. [18] Unwin C, Blatchley N, Coker W, Ferry S, Hotopf M, Hull L, et al. Health of UK servicemen who served in Persian Gulf War. Lancet. 1999;353(9148):169-78. 
[19] Kang HK, Mahan CM, Lee KY, Magee CA, Murphy FM. Illnesses among United States veterans of the Gulf War: a population-based survey of 30,000 veterans. J Occup Environ Med. 2000;42(5):491-501.

[20] IOM (Institute of Medicine). Gulf War and Health, Volume 8: Update of Health Effects of Serving in the Gulf War. Washington, DC: The National Academies Press, 2010.

[21] Hotopf M, Hull L, Fear NT, Browne T, Horn O, Iversen A, et al. The health of UK military personnel who deployed to the 2003 Iraq war: a cohort study. Lancet. 2006;367(9524):1731-41. [22] Nissen LR, Marott JL, Gyntelberg F, Guldager B. Danish soldiers in Iraq: perceived exposures, psychological distress, and reporting of physical symptoms. Mil Med. 2011;176(10):1138-43

[23] Smith TC, Powell TM, Jacobson IG, Smith B, Hooper TI, Boyko EJ, et al. Chronic multisymptom illness: a comparison of iraq and afghanistan deployers with veterans of the 1991 gulf war. Am J Epidemiol. 2014;180(12):1176-87.

[24] Quartana PJ, Wilk JE, Balkin TJ, Hoge CW. Indirect associations of combat exposure with post-deployment physical symptoms in U.S. soldiers: Roles of post-traumatic stress disorder, depression and insomnia. J Psychosom Res. 2015;78(5):478-83.

[25] Toblin RL, Riviere LA, Thomas JL, Adler AB, Kok BC, Hoge CW. Grief and physical health outcomes in U.S. soldiers returning from combat. J Affect Disord. 2012;136(3):469-75. [26] McAndrew LM, D'Andrea E, Lu SE, Abbi B, Yan GW, Engel C, et al. What predeployment and early post-deployment factors predict health function after combat deployment?: a prospective longitudinal study of Operation Enduring Freedom (OEF)/Operation Iraqi Freedom (OIF) soldiers. Health Qual Life Outcomes. 2013;11(1):73. 
[27] Horn O, Hull L, Jones M, Murphy D, Browne T, Fear NT, et al. Is there an Iraq war syndrome? Comparison of the health of UK service personnel after the Gulf and Iraq wars. Lancet. 2006;367(9524):1742-6.

[28] Ryan MA, Smith TC, Smith B, Amoroso P, Boyko EJ, Gray GC, et al. Millennium Cohort: enrollment begins a 21-year contribution to understanding the impact of military service. J Clin Epidemiol. 2007;60(2):181-91.

[29] Smith TC. The US Department of Defense Millennium Cohort Study: career span and beyond longitudinal follow-up. J Occup Environ Med. 2009;51(10):1193-201.

[30] Spitzer RL, Kroenke K, Williams JB. Validation and utility of a self-report version of PRIME-MD: the PHQ primary care study. Primary Care Evaluation of Mental Disorders. Patient Health Questionnaire. JAMA. 1999;282(18):1737-44.

[31] Kroenke K, Spitzer RL, Williams JB. The PHQ-15: validity of a new measure for evaluating the severity of somatic symptoms. Psychosom Med. 2002;64(2):258-66.

[32] Hoge CW, Terhakopian A, Castro CA, Messer SC, Engel CC. Association of posttraumatic stress disorder with somatic symptoms, health care visits, and absenteeism among Iraq war veterans. Am J Psychiatry. 2007;164(1):150-3.

[33] Smith TC, Smith B, Jacobson IG, Corbeil TE, Ryan MA, for the Millennium Cohort Study Team. Reliability of standard health assessment instruments in a large, population-based cohort study. Ann Epidemiol. 2007;17(7):525-32.

[34] Kroenke K, Spitzer RL, Williams JB. The PHQ-9: validity of a brief depression severity measure. J Gen Intern Med. 2001;16(9):606-13.

[35] American Psychiatric Association. Diagnostic and Statistical Manual of Mental Disorders. 4th Ed. Washington, DC: American Psychiatric Association; 2000. 
[36] Weathers F, Litz B, Herman D, Huska J, Keane T. The PTSD Checklist (PCL): reliability, validity, and diagnostic utility. Paper presented at the Annual Meeting of International Society for Traumatic Stress Studies; San Antonio, TXOctober 25, 1993.

[37] Spitzer RL, Williams JB, Kroenke K, Hornyak R, McMurray J. Validity and utility of the PRIME-MD patient health questionnaire in assessment of 3000 obstetric-gynecologic patients: the PRIME-MD Patient Health Questionnaire Obstetrics-Gynecology Study. Am J Obstet Gynecol. 2000;183(3):759-69.

[38] Ferraro K, Farmer M. Utility of health data from social surveys: is there a gold standard for measuring morbidity? Am Sociol Rev. 1999;64(2):303-15.

[39] Fitzmaurice GM, Laird NM, Ware JH. Longitudinal Data Analysis. Hoboken, N.J.: John Wiley \& Sons, Inc.; 2004.

[40] Liu X, Engel CC. Predicting longitudinal trajectories of health probabilities with randomeffects multinomial logit regression. Stat Med. 2012;31(29):4087-101.

[41] Hoge CW, Castro CA. Post-traumatic stress disorder in UK and US forces deployed to Iraq. Lancet. 2006;368(9538):837; author reply

[42] Sundin J, Herrell RK, Hoge CW, Fear NT, Adler AB, Greenberg N, et al. Mental health outcomes in US and UK military personnel returning from Iraq. Br J Psychiatry. 2014. [43] Defense Manpower Data Center. Armed Forces Strength Figures for September 30, 2014. Available from: https://www.dmdc.osd.mil/appj/dwp/dwp_reports.jsp, Accessed November 17, 2013.

[44] Falvo MJ, Serrador JM, McAndrew LM, Chandler HK, Lu SE, Quigley KS. A retrospective cohort study of U.S. service members returning from Afghanistan and Iraq: is physical health worsening over time? BMC Public Health. 2012;12:1124. 
[45] Kroenke K. A practical and evidence-based approach to common symptoms: a narrative review. Ann Intern Med. 2014;161(8):579-86.

[46] Sharpe M, Mayou R, Walker J. Bodily symptoms: new approaches to classification. J Psychosom Res. 2006;60(4):353-6.

[47] Croicu C, Chwastiak L, Katon W. Approach to the patient with multiple somatic symptoms. Med Clin North Am. 2014;98(5):1079-95.

[48] Bair MJ, Ang D, Wu J, Outcalt SD, Sargent C, Kempf C, et al. Evaluation of Stepped Care for Chronic Pain (ESCAPE) in Veterans of the Iraq and Afghanistan Conflicts: A Randomized Clinical Trial. JAMA Intern Med. 2015.

[49] Dobscha SK, Corson K, Perrin NA, Hanson GC, Leibowitz RQ, Doak MN, et al. Collaborative care for chronic pain in primary care: a cluster randomized trial. JAMA. 2009;301(12):1242-52.

[50] Kroenke K, Bair MJ, Damush TM, Wu J, Hoke S, Sutherland J, et al. Optimized antidepressant therapy and pain self-management in primary care patients with depression and musculoskeletal pain: a randomized controlled trial. JAMA. 2009;301(20):2099-110. [51] Kroenke K, Krebs EE, Wu J, Yu Z, Chumbler NR, Bair MJ. Telecare collaborative management of chronic pain in primary care: a randomized clinical trial. JAMA. 2014;312(3):240-8.

[52] Wells TS, Jacobson IG, Smith TC, Spooner CN, Smith B, Reed RJ, et al. Prior health care utilization as a potential determinant of enrollment in a 21-year prospective study, the Millennium Cohort Study. Eur J Epidemiol. 2008;23(2):79-87. 
[53] LeardMann CA, Smith B, Smith TC, Wells TS, Ryan MA, for the Millennium Cohort Study Team. Smallpox vaccination: comparison of self-reported and electronic vaccine records in the Millennium Cohort Study. Hum Vaccin. 2007;3(6):245-51.

[54] Smith B, Leard CA, Smith TC, Reed RJ, Ryan MA. Anthrax vaccination in the Millennium Cohort: validation and measures of health. Am J Prev Med. 2007;32(4):347-53.

[55] Smith B, Wingard DL, Ryan MA, Macera CA, Patterson TL, Slymen DJ, et al. U.S. military deployment during 2001-2006: comparison of subjective and objective data sources in a large prospective health study. Ann Epidemiol. 2007;17(12):976-82.

[56] Littman AJ, Boyko EJ, Jacobson IG, Horton J, Gackstetter GD, Smith B, et al. Assessing nonresponse bias at follow-up in a large prospective cohort of relatively young and mobile military service members. BMC Med Res Methodol. 2010;10:99. 
Table 1. Characteristics of Millennium Cohort Participants by Multiple Physical Symptoms

Status at Baseline

\section{Baseline (Wave 1)}

\begin{tabular}{|c|c|c|c|}
\hline & $\begin{array}{c}\text { Total Sample } \\
(n=75938) \\
N(\%) \text { or M (SD) }\end{array}$ & $\begin{array}{c}\text { MPS Negative } \\
(n=69317) \\
N(\%) \text { or M (SD) }\end{array}$ & $\begin{array}{c}\text { MPS Positive } \\
(n=6621) \\
N(\%) \text { or M (SD) }\end{array}$ \\
\hline Baseline age, years & $33.76(9.15)$ & $33.88(9.13)$ & $32.46(9.26)$ \\
\hline Sex, male & $55659(73.3)$ & $52216(75.3)$ & $3443(52.0)$ \\
\hline \multicolumn{4}{|l|}{ Race/ethnicity } \\
\hline White, non-Hispanic & $52892(69.7)$ & $48654(70.2)$ & $4238(64.0)$ \\
\hline Black, Non-Hispanic & $10388(13.7)$ & $9094(13.1)$ & $1294(19.6)$ \\
\hline Other & $12596(16.6)$ & $11513(13.1)$ & $1085(16.4)$ \\
\hline \multicolumn{4}{|l|}{ Service branch } \\
\hline Army & $35924(47.3)$ & $32091(46.3)$ & $3833(57.9)$ \\
\hline Navy & $13257(17.5)$ & $12198(17.6)$ & $1059(16.0)$ \\
\hline Marine Corps & $3837(5.1)$ & $3494(5.0)$ & $343(5.2)$ \\
\hline Air Force & $22098(29.1)$ & $20766(30.0)$ & $1332(20.1)$ \\
\hline Coast Guard & $822(1.1)$ & $768(1.1)$ & $54(0.8)$ \\
\hline \multicolumn{4}{|l|}{ Military pay grade } \\
\hline Enlisted & $58430(76.9)$ & $52405(75.6)$ & $6025(91.0)$ \\
\hline Officer & $17508(23.1)$ & $16912(24.4)$ & $596(9.0)$ \\
\hline \multicolumn{4}{|l|}{ Deployed to OIF/OEF } \\
\hline No & $71787(94.5)$ & $65404(94.4)$ & $6383(96.4)$ \\
\hline Yes & $4151(5.5)$ & $3913(5.6)$ & $238(3.6)$ \\
\hline Number of physical conditions $\mathrm{s}^{\mathrm{a}}$ & $0.51(1.67)$ & $0.45(1.64)$ & $1.11(1.83)$ \\
\hline \multicolumn{4}{|l|}{ Depression $^{\mathrm{b}}$} \\
\hline No & $68417(90.9)$ & $64479(93.8)$ & $3938(60.4)$ \\
\hline Yes & $6867(9.1)$ & $4285(6.2)$ & $2582(39.6)$ \\
\hline \multicolumn{4}{|l|}{ PTSD $^{c}$} \\
\hline No & $69881(94.5)$ & $65491(96.8)$ & $4390(69.4)$ \\
\hline Yes & $4082(5.5)$ & $2150(3.2)$ & $1932(30.6)$ \\
\hline \multicolumn{4}{|l|}{ Anxiety and/or panic ${ }^{d}$} \\
\hline No & $72666(97.1)$ & 67608 (98.9) & $5058(78.1)$ \\
\hline Yes & $2197(2.9)$ & $776(1.1)$ & $1421(21.9)$ \\
\hline
\end{tabular}

Abbreviations: DSM-IV, Diagnostic and Statistical Manual of Mental Disorders, 4th Edition; OEF/OIF, Operation Enduring Freedom/Operation Iraqi Freedom; PHQ, Patient Health Questionnaire; PTSD, posttraumatic stress disorder. ${ }^{a}$ Based on self-report of ever being diagnosed with any of 24 listed serious and chronic physical conditions (angina, asthma, Crohn's disease, coronary heart disease, chronic bronchitis, cirrhosis, cancer, diabetes, emphysema, heart attack, hepatitis A, hepatitis B, other hepatitis, significant hearing loss, hypertension, kidney failure requiring dialysis, lupus, multiple sclerosis, neuropathy-caused reduced sensation in hands or feet, pancreatitis, rheumatoid arthritis, stroke, ulcerative colitis or proctitis, stomach/duodenal/peptic ulcer); $n=75768$.

${ }^{\mathrm{b}}$ Based on the PHQ using standard diagnostic algorithm for depression and/or self-reported depression diagnosis by a health professional; $n=75284$. 
${ }^{c}$ Based on the PTSD Checklist-Civilian Version, using DSM-IV sensitive diagnostic criteria and/or self-reported PTSD diagnosis by a health professional; $n=73963$.

${ }^{\mathrm{d}}$ Based on the PHQ using standard diagnostic algorithm for anxiety and/or panic disorder; $n=74863$. 
Table 2. Pairwise Conditional Odds Ratios and 95\% Confidence Intervals of Multiple Physical Symptoms for Deployment Status at Three Time Points ${ }^{\mathrm{a}, \mathrm{b}}$

\begin{tabular}{|c|c|c|c|c|c|c|}
\hline \multirow[t]{2}{*}{ Deployment Status } & \multicolumn{2}{|c|}{ Wave 1} & \multicolumn{2}{|c|}{ Wave 2} & \multicolumn{2}{|c|}{ Wave 3} \\
\hline & OR & $95 \% \mathrm{CI}$ & OR & $95 \% \mathrm{CI}$ & OR & $95 \% \mathrm{CI}$ \\
\hline $\begin{array}{c}\text { Deployed with combat } \\
\text { (ref = not deployed) }\end{array}$ & 1.49 & $1.47,1.52$ & 1.73 & $1.69,1.78$ & 2.08 & $2.03,2.12$ \\
\hline $\begin{array}{l}\text { Deployed without combat } \\
\quad(\text { ref }=\text { not deployed })\end{array}$ & 0.56 & $0.54,0.58$ & 0.96 & $0.95,0.96$ & 1.23 & $1.23,1.24$ \\
\hline $\begin{array}{l}\text { Deployed with combat } \\
\text { (ref }=\text { deployed without combat) }\end{array}$ & 2.66 & $2.59,2.74$ & 1.81 & $1.75,1.87$ & 1.68 & $1.63,1.74$ \\
\hline
\end{tabular}




\begin{tabular}{|c|c|c|c|c|}
\hline $\begin{array}{l}\text { During the last } 4 \text { weeks, how much have you } \\
\text { been bothered by any of the following } \\
\text { problems? }\end{array}$ & \multicolumn{2}{|c|}{$\begin{array}{c}\text { Not } \\
\text { Bothered }\end{array}$} & $\begin{array}{l}\text { Bothered a } \\
\text { Little }\end{array}$ & $\begin{array}{l}\text { Bothered a } \\
\text { Lot }\end{array}$ \\
\hline Stomach pain & \multicolumn{2}{|l|}{0} & O & $\circ$ \\
\hline Back pain & \multicolumn{2}{|l|}{$\circ$} & 0 & o \\
\hline Pain in your arms, legs, or joints (knees, hips, etc.) & \multicolumn{2}{|l|}{ ○ } & 0 & $\mathrm{o}$ \\
\hline Pain or problems during sexual intercourse & \multicolumn{2}{|l|}{$\circ$} & 0 & 0 \\
\hline Headaches & \multicolumn{2}{|l|}{ ○ } & 0 & 0 \\
\hline Chest pain & \multicolumn{2}{|l|}{ O } & 0 & 0 \\
\hline Dizziness & \multicolumn{2}{|l|}{$\circ$} & 0 & 0 \\
\hline Fainting spells & \multicolumn{2}{|l|}{ 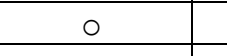 } & 0 & 0 \\
\hline Feeling your heart pound or race & \multicolumn{2}{|l|}{ O } & 0 & $\mathrm{o}$ \\
\hline Shortness of breath & \multicolumn{2}{|l|}{ ○ } & $\circ$ & 0 \\
\hline Constipation, loose bowels, or diarrhea & \multicolumn{2}{|l|}{ ○ } & $\circ$ & ○ \\
\hline Nausea, gas, or indigestion & \multicolumn{2}{|l|}{ ○ } & $\circ$ & $\circ$ \\
\hline $\begin{array}{l}\text { Women only: Menstrual cramps or other } \\
\text { problems with your periods }\end{array}$ & \multicolumn{2}{|l|}{ o } & ○ & $\circ$ \\
\hline $\begin{array}{l}\text { Over the last } 2 \text { weeks, how often have you been } \\
\text { bothered by any of the following problems? }\end{array}$ & $\begin{array}{c}\text { Not } \\
\text { at all }\end{array}$ & $\begin{array}{c}\text { Several } \\
\text { Days }\end{array}$ & $\begin{array}{l}\text { More } \\
\text { than half } \\
\text { the days }\end{array}$ & $\begin{array}{l}\text { Nearly } \\
\text { every } \\
\text { day }\end{array}$ \\
\hline $\begin{array}{l}\text { Trouble falling or staying asleep or sleeping too } \\
\text { much }\end{array}$ & o & o & 0 & $\circ$ \\
\hline Feeling tired or having little energy & $\circ$ & 0 & $\circ$ & $\circ$ \\
\hline
\end{tabular}

Figure 1. 


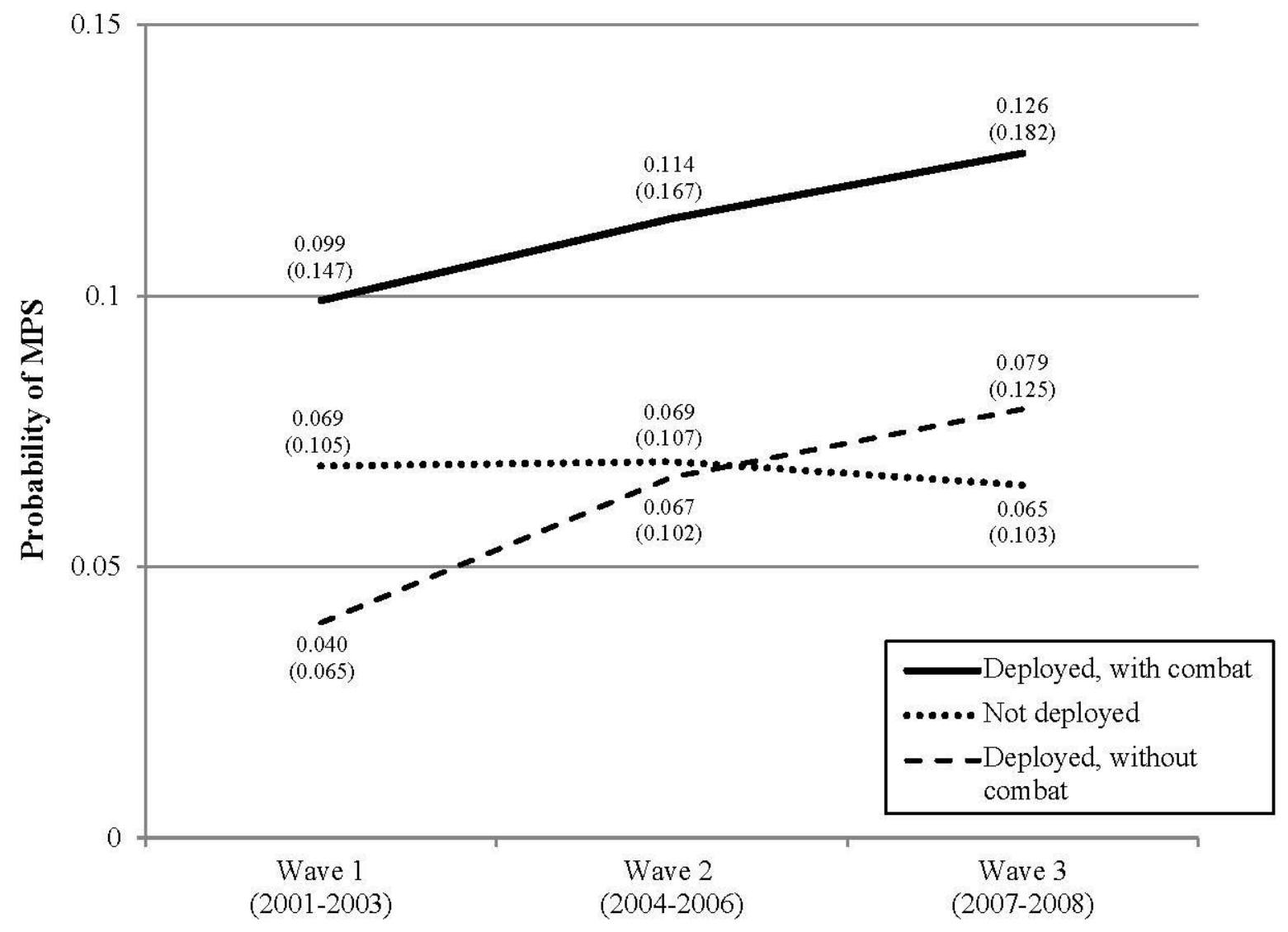

Time point

Figure 2. 